\title{
Lens thickness and associated ocular biometric factors among cataract patients in Shanghai
}

Jiaqi Meng ${ }^{1 \dagger}$, Ling Wei ${ }^{1 \dagger}$, Wenwen He $\mathrm{e}^{1,2,3,4,5}$, Jiao Qi ${ }^{1}, \mathrm{Yi} \mathrm{Lu}^{1,2,3,4,5^{*}}$ and Xiangjia Zhu $\mathrm{u}^{1,2,3,4,5^{*}}$ (D)

\begin{abstract}
Background: To evaluate the distribution of lens thickness (LT) and its associations with other ocular biometric factors among cataract patients in Shanghai.

Methods: Twenty-four thousand thirteen eyes from 24,013 cataract patients were retrospectively included. Ocular biometric factors including LT, central corneal thickness (CCT), anterior chamber depth (ACD), white-to-white (WTW) distance, anterior corneal curvature, and axial length (AL) were obtained using the IOLMaster700. The associations between LT and general or ocular factors were assessed.

Results: The mean age was $62.5 \pm 13.6$ years and $56.1 \%$ were female. The mean LT was $4.51 \pm 0.46 \mathrm{~mm}$. The LT was greater in older patients $(P<0.001)$. LT was positively correlated with $C C T$, while negatively correlated with $A C D$, WTW, and anterior corneal curvature $(P<0.001)$. Multivariate analysis revealed that increased LT was associated with older age, male gender, thicker CCT, shallower ACD, larger WTW, and flatter anterior corneal curvature $(P<0.001)$. LT changed with a variable behavior according to AL. In short eyes LT increased as AL increased, then decreased with longer AL in normal eyes and moderate myopic eyes, but increased again as AL increased in highly myopic eyes. Thickest LT was found in the 20.01-22 mm AL group. The correlation between LT and other biometric factors remained significant when stratified by ALs.

Conclusions: In a large Chinese cataractous population, we found that the thicker lens may be associated with older age, male gender, thicker CCT, shallower ACD, larger WTW, and flatter anterior corneal curvature. As AL increased, the change of LT was nonlinear, with the thickest lens seen in the 20-22 mm AL group.
\end{abstract}

Keywords: Lens thickness, Cataract, Ocular biometry, Axial length

\section{Introduction}

Currently, cataract is one of the leading causes of visual impairment worldwide [1]. With the advancement of cataract surgery and intraocular lens (IOL) design, the accurate biometric measurement has become a crucial factor in surgical planning [2]. Lens thickness (LT) is one of the important parameters in ocular biometry. Not

\footnotetext{
*Correspondence: luyieent@163.com; zhuxiangjia1982@126.com

†Jiaqi Meng and Ling Wei contributed equally to this work.

${ }^{1}$ Eye Institute and Department of Ophthalmology, Eye \& ENT Hospital, Fudan University, 83 Fenyang Road, Xuhui District, Shanghai 200031, China Full list of author information is available at the end of the article
}

only is it a necessary variable used in fourth-generation IOL formulas [3-5], but also its associations with other ocular parameters may further affect actual lens position after surgery [6]. Meanwhile, during cataract development, morphological changes of the lens may also occur along with decreased transparency $[7,8]$. Therefore, the observation of LT among cataract patients is of great importance from both clinical and pathophysiological perspectives.

Recently, accurate measurement of LT in cataractous eyes has become available due to the advancement of

C C The Author(s). 2021 Open Access This article is licensed under a Creative Commons Attribution 4.0 International License, which permits use, sharing, adaptation, distribution and reproduction in any medium or format, as long as you give appropriate credit to the original author(s) and the source, provide a link to the Creative Commons licence, and indicate if changes were made. The images or other third party material in this article are included in the article's Creative Commons licence, unless indicated otherwise in a credit line to the material. If material is not included in the article's Creative Commons licence and your intended use is not permitted by statutory regulation or exceeds the permitted use, you will need to obtain permission directly from the copyright holder. To view a copy of this licence, visit http://creativecommons.org/licenses/by/4.0/ The Creative Commons Public Domain Dedication waiver (http://creativecommons.org/publicdomain/zero/1.0/) applies to the data made available in this article, unless otherwise stated in a credit line to the data. 
optical biometry [9-11]. Based on the optical lowcoherence reflectometry (OLCR), an increased trend of LT with cataract formation was identified [9], while based on swept source optical coherence tomography (SS-OCT), Henriquez et al. found that the increase of LT was independent of lens density in mild to moderate cataract [10]. Moreover, OLCR-based LT contributes to lower refractive error compared with age-derived LT [11].

Due to changes in anatomical structures of eyeballs with different axial lengths (AL) [12], the characteristics of ocular biometry may also show variations. Longer AL is associated with higher central cornea thickness (CCT), higher corneal radius, larger corneal diameter and deeper anterior chamber depth (ACD) in normal eyes [13$15]$, but these correlations may be not present in eyes with extreme long or short AL [16, 17]. Vega et al. found that the effect of LT on the accuracy of the Barrett Universal II formula was the greatest in eyes with $\mathrm{AL} \leq 22$ $\mathrm{mm}$ but less in eyes with $\mathrm{AL} \geq 26 \mathrm{~mm}$ [18]. Even among patients with normal ALs $(22-26 \mathrm{~mm})$, a higher prediction error may be seen with an extreme LT, especially for the Haigis and Hill-RBF V2.0 formulas [19]. Thus, investigating the distribution of $\mathrm{LT}$ against $\mathrm{AL}$ is required. Previously, reports on LT were seen in countries such as Peru, the United States, Iran and Portugal [10, 13, 20, 21]. A thinner lens was reported in the Iranian or Portuguese population than the Peruvian or American study, indicating a potential racial difference in LT. With higher prevalence of myopia and high myopia in Asia, the lens geometry of Asian eyes may also be different from that of Caucasian eyes. However, no reports on LT have been published that include a large sample of Asian cataractous eyes.

Thus, in this study, based on a large sample, we aimed to investigate the distribution and associated ocular biometric factors of LT in cataractous eyes in Shanghai, and also to focus on the influence of AL on LT.

\section{Methods}

The protocols for this retrospective observational study were approved by the Institutional Review Board of the Eye and Ear, Nose, Throat (EENT) Hospital of Fudan University, Shanghai, China (ID: 2014055). The study adhered to the tenets of the Declaration of Helsinki. Written informed consent for the use of clinical data was routinely obtained from each patient before cataract surgery.

\section{Patients}

Ocular biometry data of patients who had cataract surgery between March 2018 and March 2020 were reviewed. Patients aged 18 years or older were included. We excluded eyes with marked corneal abnormalities that would affect measurement (e.g., dense corneal scars, keratoconus, and irregular astigmatism), lens dislocations, active ocular inflammation, and previous trauma or intraocular surgery. When both eyes of a patient met the criteria, we randomly selected one eye from each patient for analysis using the random number table. In brief, the left eye was included if the patient was given an odd random number, otherwise the right eye was included. For patients in whom only one eye met the criteria, that eye was included. Finally, a total of 24,013 eyes of 24,013 patients were available for analysis.

\section{Ocular biometric measurements}

For each eye, ocular biometric factors, including LT, CCT, ACD, white-to-white (WTW) distance, anterior corneal curvature and $\mathrm{AL}$, were measured using a swept-source optical coherence tomography (OCT) based biometer (IOLMaster700, version 1.80; Carl Zeiss Meditec, Jena, Germany). For this device, axial measurements, including LT, CCT and ACD are based on swept-source frequency-domain optical coherence tomography with a $44 \mathrm{~mm}$ scan depth and $22 \mathrm{~mm}$ tissue resolution. LT was defined as the distance between the anterior and posterior poles of the crystalline lens. CCT was defined as the distance between the corneal epithelium and endothelium. ACD was defined as the distance between the corneal endothelium and anterior crystalline lens surface. The device also uses a scleral and iris image for WTW measurement, and the reflected light spots on the corneal surface for anterior corneal curvature measurement. All measurements were routinely performed by experienced technical staff in a single examination lane within the same institution using a single IOLMaster700 device. During each measurement, the technical staff visually checked the eye geometry and axis of the measurements on the scan image of the entire eye, and ensured the correct fixation by the patient on the foveal scan. For each measurement, the device calculates the standard deviation (SD) for LT, ACD and $\mathrm{AL}$ and warned of poor-quality results if the SD for LT > $0.038 \mathrm{~mm}$, for $\mathrm{ACD}>0.021 \mathrm{~mm}$ and for $\mathrm{AL}>0.027 \mathrm{~mm}$ [22]. Measurements with poor-quality results were deleted and remeasured until reproducible readings were obtained. Data were stored in a spreadsheet before being input into SPSS software for analysis.

In this study, the eyes were further divided into eight groups according to the $\mathrm{AL}(\mathrm{AL} \leq 20 \mathrm{~mm}, 20.01-$ $22 \mathrm{~mm}, 22.01-24.5 \mathrm{~mm}, 24.51-26 \mathrm{~mm}, 26.01-28 \mathrm{~mm}$, 28.01-30 mm, 30.01-35 mm, and > $35 \mathrm{~mm}$ ), Then, eyes with $\mathrm{AL} \leq 22 \mathrm{~mm}$ were defined as short eyes, those with AL ranging from 22.01 to $24.5 \mathrm{~mm}$ were defined as normal eyes, those with AL ranging from 24.51 to $26 \mathrm{~mm}$ were defined as moderate myopic eyes, and those with $\mathrm{AL}>26 \mathrm{~mm}$ were defined as highly myopic eyes. 


\section{Statistical analyses}

Continuous data were presented as means \pm standard deviations and categorical data were presented as proportions (\%). Kolmogorov-Smirnov test was used to assess normality. Mann-Whitney $U$ test or Kruskal-Wallis test was used to compare continuous data between groups or among three or more groups. Analysis of covariance (ANCOVA) was used to compare the LT between groups or among three or more groups after adjustment for age. The Pearson correlation analysis was used to assess the associations between LT and general or other biometric parameters. The stepwise backwards multiple linear regression analysis was performed with $\mathrm{LT}$ as the dependent variable and general or other ocular biometric factors as independent variables. The oddsratio (OR) was calculated using a binary logistic regression model, in which a thick lens (LT $>4.51 \mathrm{~mm}$ ) was defined as 1 and a thin lens ( $\mathrm{LT} \leq 4.51 \mathrm{~mm})$ was defined as 0 . All statistical analyses were performed with SPSS version 22 (SPSS, Chicago, IL, USA). Two-sided $P$ values $<0.05$ were considered statistically significant for all analyses.

\section{Results}

\section{Characteristics}

Table 1 lists the general and ocular characteristics of the study population. Of the included 24,013 patients, the mean age was $62.5 \pm 13.6$ years (Median, 64.0 years; Range, $18.0-101.0$ years), and 13,450 (56.1\%) were female. The mean AL was $24.71 \pm 2.81 \mathrm{~mm}$; Range, 14.07$37.96 \mathrm{~mm}$.

Figure 1 shows the frequency distribution of LT among the study population, with a mean value of $4.51 \pm 0.46 \mathrm{~mm}$ (Median, $4.51 \mathrm{~mm}$; Range, 2.49-6.36 mm).

\section{Comparisons of LT according to age and gender}

LT stratified by age and gender is presented in Table 2 . When LT was stratified by age, in either men or women, LT was significantly greater in older patients (KruskalWallis test, $P<0.001)$. When stratified by gender, LT

Table 1 Study population characteristics

\begin{tabular}{ll}
\hline & Total $(\mathbf{N}=\mathbf{2 4 , 0 1 3})$ \\
\hline Age (years) & $62.5 \pm 13.6$ \\
Sex (male/female) & $10,563 / 13450$ \\
Eye laterality (right/left) & $11,843 / 12170$ \\
CCT $(\mathrm{mm})$ & $0.55 \pm 0.04$ \\
ACD $(\mathrm{mm})$ & $2.52 \pm 0.48$ \\
WTW $(\mathrm{mm})$ & $11.70 \pm 0.46$ \\
Anterior corneal curvature $(\mathrm{mm})$ & $7.69 \pm 0.28$ \\
AL (mm) & $24.71 \pm 2.81$ \\
\hline CCT centra con
\end{tabular}

$C C T$ central corneal thickness; $A C D$ anterior chamber depth; WTW white-towhite; $A L$ axial length was generally greater in men than in women (ANCOVA, $P<0.001)$. Of note, in patients aged 60-69 years and $70-79$ years, LT was significantly greater in men than in women (Mann-Whitney $U$ test, both $P<0.05$ ), while no differences were found between men and women in the other age groups (all $P>0.05$ ).

\section{Associations between LT and general or ocular biometric factors}

Univariate analysis revealed that LT was positively correlated with age and CCT, while negatively correlated with $\mathrm{ACD}, \mathrm{WTW}$, and anterior corneal curvature (Pearson correlation analysis; all $P<0.001$; Fig. 2). In addition, based on a regression model using AL, ACD and age for $\mathrm{LT}$, the predicted $\mathrm{LT}$ versus the $\mathrm{LT}$ measured by the IOLMaster700 was plotted in Fig. 3 (predicted $\mathrm{LT}=$ $0.226 * \mathrm{AL}-0.664 * \mathrm{ACD}+0.280 *$ age) . This model yielded an adjusted $\mathrm{R}^{2}$ of 0.53 . The LT measured by the IOLMaster700 could be predicted with a correlation coefficient of $0.73(P<0.001)$, and $89.2 \%$ of the cases had a prediction error within $0.50 \mathrm{~mm}$ of the target.

Binary logistic regression model using general and ocular biometric factors for LT revealed that a thick lens was more likely to be seen in cases of older age (OR, 1.058; 95\%CI, 1.054-1.061; $P<0.001$ ), male gender (OR, 1.763; 95\% CI, 1.643-1.893; $P<0.001)$, thicker CCT (OR, 1.326; 95\% CI, 1.241-1.417; $P<0.001$ ), shallower ACD (OR, 0.013; 95\% CI, 0.012-0.015; $P<0.001$ ), larger WTW (OR, 3.362; 95\% CI, 3.067-3.685; $P<0.001$ ), flatter anterior corneal curvature (OR, 0.334; $95 \% \mathrm{CI}$, $0.290-0.385 ; P<0.001)$ or longer AL (OR, 1.259; $95 \%$ CI, 1.242-1.277; $P<0.001$ ).

\section{Distribution and association of LT in different AL groups}

The percentages of short, normal, moderate myopic and highly myopic eyes were $6.2 \%$ (1493 eyes), 57.5\% (13,801 eyes), $13.0 \%$ (3132 eyes) and 23.3\% (5587 eyes), respectively. Table 3 shows the comparisons of LT according to AL. After adjustment for age and gender, LT was greatest in the 20.01-22 mm AL group and was smallest in the $26.01-28 \mathrm{~mm}$ AL group $(P<0.001)$. As for highly myopic eyes, LT increased gradually with the increased $\mathrm{AL}$, and when the $\mathrm{AL}$ was greater than $35 \mathrm{~mm}$, it reached a peak level of $4.72 \pm 0.47 \mathrm{~mm}$.

The scattergram of LT against AL showed poor linearity of the fitting curve (Fig. 4a). In both short and highly myopic eyes, LT was positively correlated with AL (Pearson correlation analysis, both $P<0.001$ ), while in normal eyes, LT was negatively correlated with AL $(P<0.001)$. No significant correlation was identified between LT and AL in moderate myopic eyes $(P>0.05)$. From Fig. $4 \mathrm{~b}$, in short eyes, LT increased as AL increased, then decreased with longer AL in the normal eyes and moderate myopic 


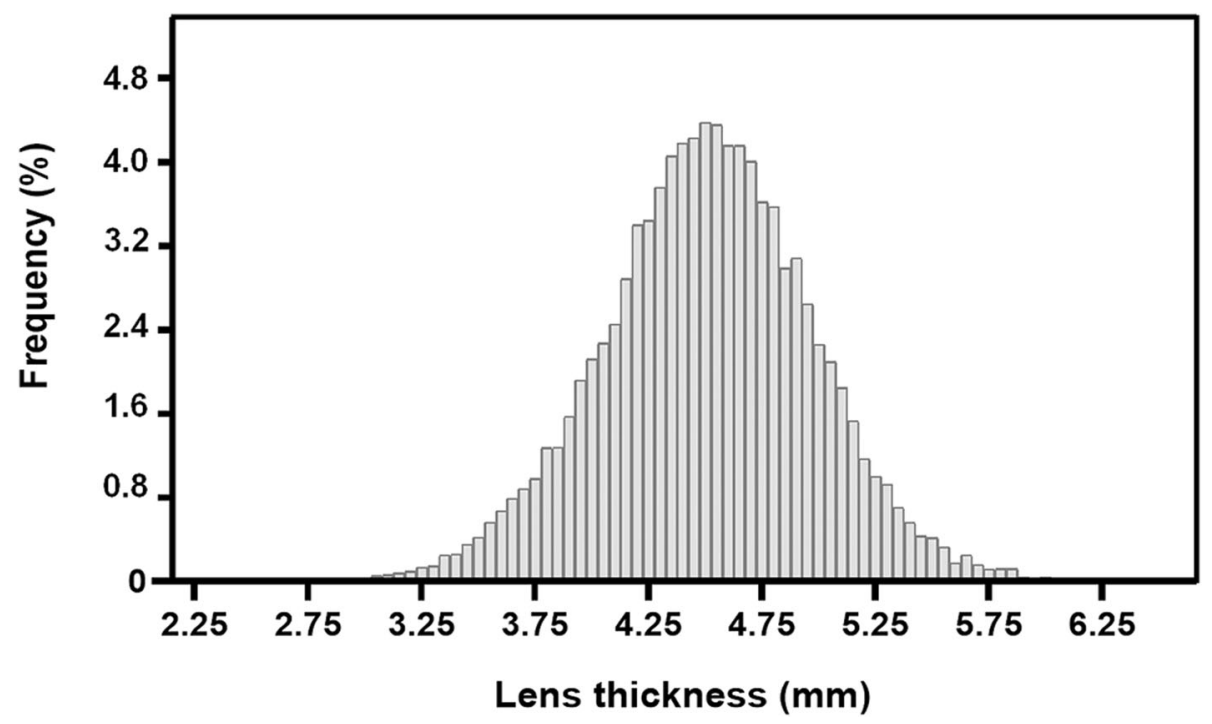

Fig. 1 Frequency distribution of lens thickness among the study population

eyes, and finally LT again increased as AL increased in highly myopic eyes.

In terms of the associations between LT and other ocular biometric factors (Table 4), multivariate analysis showed that greater LT was associated with thicker CCT, shallower ACD, larger WTW, and flatter anterior corneal curvature within each AL group (all $P<0.05$ ), after adjustment for age, sex, and eye laterality (right/left).

\section{Discussion}

In the last two decades, given the more predictable refractive results of modern phacoemulsification, surgeons have given increasing importance to the use of optical biometers, which have proven to be accurate and quite comparable in many of their measurements [23, 24]. This technological support, together with developments in IOL platforms, has allowed an important growth of refractive cataract surgery [25]. Furthermore, since the IOLMaster700 was introduced in 2014, it became the first representative of a new family of optical biometers based on SS-OCT where it had an increased ability to evaluate advanced cataracts and measure LT very precisely, which was not possible with most optical biometers based on partial coherence interferometry [22].

As one of the important biometric parameters, LT not only plays an increasingly important role in the surgical planning of cataract patients $[6,26]$, but also correlates to morphological changes in the lens with aging or cataract formation $[7,8]$. Based on a large sample of Chinese

Table 2 Lens thickness stratified by age and gender

\begin{tabular}{|c|c|c|c|c|c|c|c|}
\hline \multirow{3}{*}{$\begin{array}{l}\text { Age } \\
\text { (years) }\end{array}$} & \multicolumn{3}{|l|}{ Men } & \multicolumn{3}{|l|}{ Women } & \multirow{3}{*}{$\begin{array}{l}P \\
\text { value }\end{array}$} \\
\hline & \multirow[t]{2}{*}{$\mathrm{N}(\%)$} & \multicolumn{2}{|c|}{ Lens thickness (mm) } & \multirow[t]{2}{*}{$\mathrm{N}(\%)$} & \multicolumn{2}{|c|}{ Lens thickness (mm) } & \\
\hline & & Mean \pm SD & $95 \% \mathrm{Cl}$ & & Mean \pm SD & $95 \% \mathrm{Cl}$ & \\
\hline$<30^{a}$ & $386(3.7 \%)$ & $3.70 \pm 0.39$ & {$[3.66,3.74]$} & $243(1.8 \%)$ & $3.72 \pm 0.45$ & {$[3.66,3.78]$} & 0.576 \\
\hline $30-39^{a}$ & $614(5.8 \%)$ & $4.00 \pm 0.42$ & {$[3.97,4.03]$} & $395(2.9 \%)$ & $4.01 \pm 0.46$ & {$[3.97,4.06]$} & 0.584 \\
\hline $40-49^{a}$ & $1241(11.7 \%)$ & $4.26 \pm 0.38$ & {$[4.24,4.29]$} & $910(6.8 \%)$ & $4.30 \pm 0.46$ & {$[4.27,4.33]$} & 0.152 \\
\hline $50-59^{a}$ & 2095 (19.8\%) & $4.44 \pm 0.40$ & {$[4.42,4.46]$} & $2510(18.7 \%)$ & $4.42 \pm 0.41$ & {$[4.40,4.43]$} & 0.091 \\
\hline $60-69^{a}$ & $3066(29.0 \%)$ & $4.60 \pm 0.41$ & {$[4.58,4.61]$} & $5047(37.5 \%)$ & $4.55 \pm 0.41$ & {$[4.54,4.56]$} & $<0.001$ \\
\hline $70-79^{a}$ & $2264(21.4 \%)$ & $4.67 \pm 0.42$ & {$[4.65,4.69]$} & $3213(23.9 \%)$ & $4.64 \pm 0.42$ & {$[4.63,4.66]$} & 0.012 \\
\hline$\geq 80^{a}$ & 897 (8.5\%) & $4.79 \pm 0.41$ & {$[4.76,4.82]$} & 1132 (8.4\%) & $4.76 \pm 0.41$ & {$[4.74,4.79]$} & 0.105 \\
\hline Total $^{b}$ & $10,563(100 \%)$ & $4.52 \pm 0.47$ & {$[4.51,4.53]$} & $13,450(100 \%)$ & $4.50 \pm 0.46$ & {$[4.49,4.51]$} & $<0.001$ \\
\hline
\end{tabular}

$S D$ standard deviation; $C l$ confidence interval

${ }^{a}$ Mann-Whitney $U$ test

${ }^{\mathrm{b}}$ Analysis of covariance after adjusting for age 


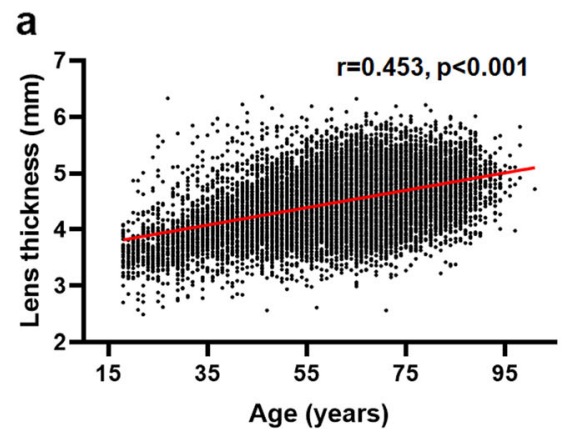

C

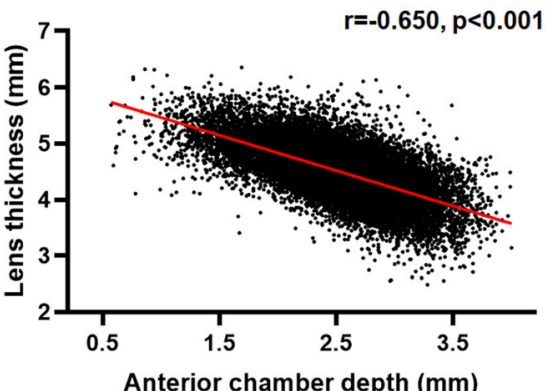

b

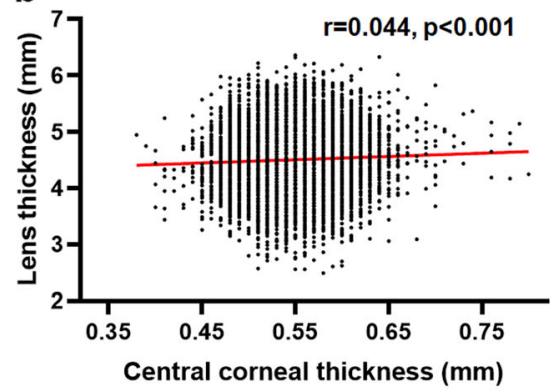

d

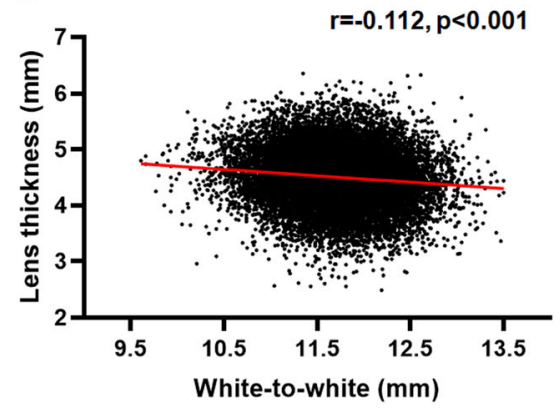

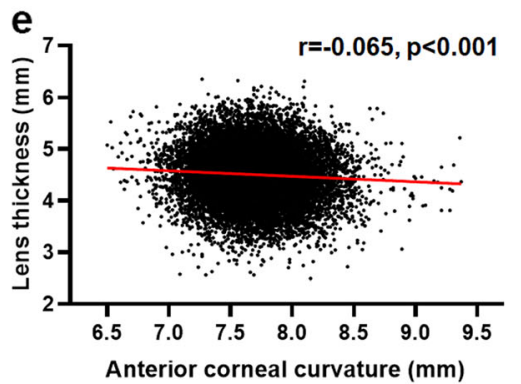

Fig. 2 The correlation between lens thickness and age and ocular biometric factors. Scatter plots showing the correlation between lens thickness and age (a), central corneal thickness (b), anterior chamber depth (c), white-to-white distance (d), and anterior corneal curvature (e) in cataract patients. The red straight line refers to the corresponding equation resulting from the linear regression analyses. Multivariate analysis showed that the thicker lens was associated with older age $(\beta=0.295, P<0.001)$, male gender $(\beta=0.103, P<0.001)$, thicker central corneal thickness $(\beta=$ $0.058, P<0.001)$, shallower anterior chamber depth $(\beta=-0.748, P<0.001)$, larger white-to-white distance $(\beta=0.204, P<0.001)$, and flatter anterior corneal curvature $(\beta=-0.113, P<0.001)$

patients, we reported the distribution of LT in cataractous eyes with the mean value being $4.51 \pm 0.46 \mathrm{~mm}$. Previously, Klein et al. measured LT from slit lamp photographs and reported a mean value of $6.17 \mathrm{~mm}$ [20], which was apparently higher compared to the studies using ultrasound or optical biometry. However, for ultrasound biometry, the mean LT varied significantly from $3.95 \mathrm{~mm}$ to $4.94 \mathrm{~mm}$ in previous studies $[27,28]$. Recently, with the advancement of optical biometry, LT can be measured precisely in cataractous eyes [22]. Our result was similar to those of the studies based on the Lenstar LS $900(4.59 \mathrm{~mm})$ and IOLMaster700 $(4.56 \mathrm{~mm})[10,28]$. Besides, the average LT of the Asian eyes in our study was similar to those of previous studies on cataract patients in North America and Southeast Asia, such as $4.38 \mathrm{~mm}$ in the Los Angeles Latino Eye Study [29], $4.51 \mathrm{~mm}$ in the Meiktila Eye Study [30], and $4.62-4.79 \mathrm{~mm}$ in the Tanjong Pagar Survey [31]. Moreover, LT was found to be significantly related to age in the study population. The increasing trend of LT with age, which is consistent with previous observations on human adults and animal models [27, 32], may result from the continuous accretion of lens fibers in the equatorial region of the lens [7]. Pertaining to gender, the correlation between a thicker lens and the male gender has also been reported by previous studies, such as the Beaver Dam Eye Study and the Central India Eye and Medical Study [20, 27], which may be paralleled by similar associations between $\mathrm{AL}$ and male gender [33]. 


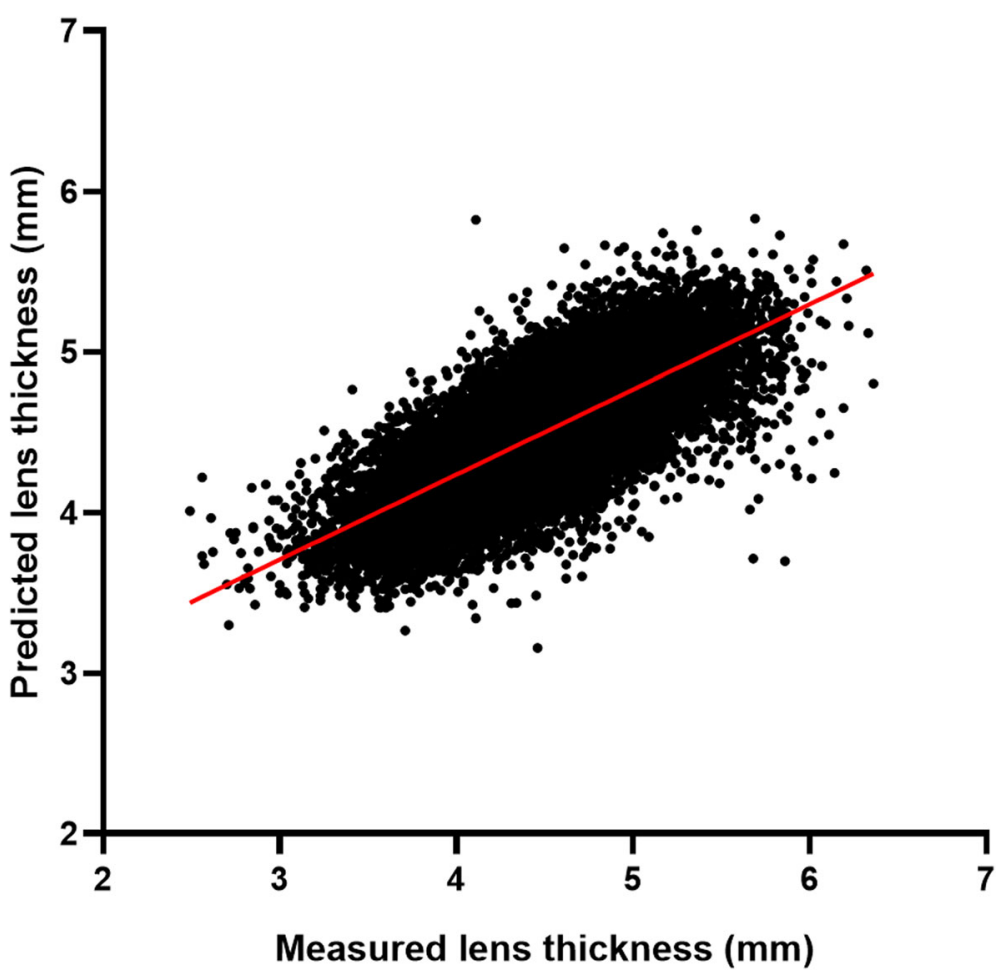

Fig. 3 Predicted lens thickness versus preoperative lens thickness measured by the IOLMaster700 in 24,013 Asian cataractous eyes. The predicted lens thickness was calculated using a regression model including age, axial length, anterior chamber depth. The correlation coefficient was $0.73(P<0.001)$

LT, as a factor of the anterior segment anatomy, may be closely related to the biometric factors that further influence the estimation of postoperative position of IOL $[11,34]$, though it was not included in several previous IOL calculation formulas $[35,36]$. Recently, newgeneration formulas including the Olsen, Holladay 2 and Barrett Universal II formulas also rely on LT and have shown improved prediction accuracy [3-5]. For cataract surgeons today, we recommend LT to be introduced in

Table 3 Comparison of lens thickness according to axial length

\begin{tabular}{llll}
\hline AL $(\mathbf{m m})$ & $\mathbf{N}(\%)$ & $\mathbf{L T}(\mathbf{m m})$ & \\
\cline { 3 - 4 } & & Mean \pm SD & $\mathbf{9 5 \% ~ C I}$ \\
\hline$\leq 20$ & $159(0.7 \%)$ & $4.62 \pm 0.49$ & {$[4.54,4.69]$} \\
$20.01-22$ & $1334(5.6 \%)$ & $4.75 \pm 0.45$ & {$[4.73,4.78]$} \\
$22.01-24.5$ & $13,776(57.4 \%)$ & $4.55 \pm 0.45$ & {$[4.54,4.56]$} \\
$24.51-26$ & $3157(13.1 \%)$ & $4.39 \pm 0.47$ & {$[4.38,4.41]$} \\
$26.01-28$ & $2435(10.1 \%)$ & $4.33 \pm 0.45$ & {$[4.31,4.35]$} \\
$28.01-30$ & $1463(6.1 \%)$ & $4.38 \pm 0.45$ & {$[4.35,4.40]$} \\
$30.01-35$ & $1608(6.7 \%)$ & $4.53 \pm 0.43$ & {$[4.51,4.55]$} \\
$>35$ & $81(0.3 \%)$ & $4.72 \pm 0.47$ & {$[4.62,4.83]$} \\
P value* & & $<0.001$ & \\
\hline
\end{tabular}

$A L$ axial length; $L T$ lens thickness; $C l$ confidence interval * Multivariate analysis after adjustment for age and gender
IOL power calculation, and that new-generation formulas that are less influenced by LT [37], such as Barrett Universal II, Kane, PEARL-DGS, and EVO V2.0 may be applied. In this study, multiple risk factors for LT were identified, including older age, male gender, thicker central cornea, shallower ACD, larger WTW, and flatter anterior corneal curvature. For patients with these characteristics, surgeons need to know whether they have extreme LT before surgery, which may result in a greater hyperopic shift after surgery [19], and then proceed to use IOL formulas to gain a stable performance in a wide range of LT.

In our study, the association of LT with CCT agrees with previous reports [37], suggesting that the thicker lens may correspond with a thicker cornea. Moreover, we identified a negative correlation between LT and ACD. With the progression of cataract, the lens tends to thicken bi-directionally, which may result in a shallower anterior chamber [38]. Due to this correlation, IOL formula bias may be expected when the preoperative $\mathrm{ACD}$ is used alone rather than in combination with the LT, though the statistical correlation between the preoperative ACD and the postoperative position of the IOL has been widely proven [6]. Another interesting observation is the positive correlation between LT and WTW. In clinical practice, the WTW may provide helpful 

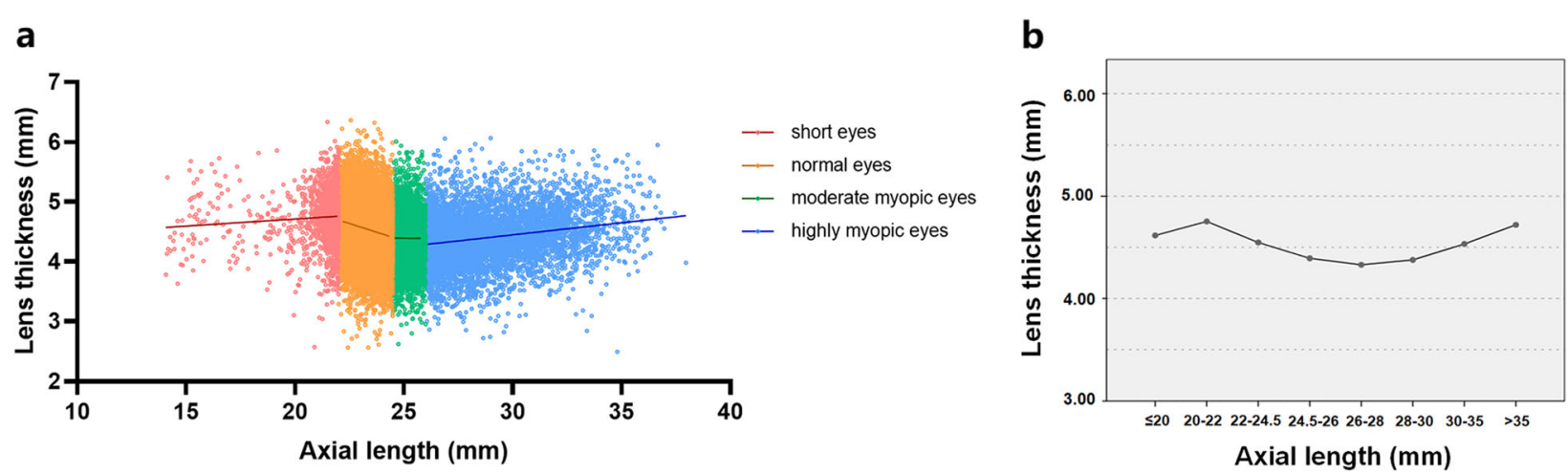

Fig. 4 Distribution of lens thickness in dependence of the axial length. a Scatter plot showing the LT against AL among cataract patients. In short eyes, the equation resulting from the linear regression analysis (red line) was: $\mathrm{LT}(\mathrm{mm})=0.024 \mathrm{AL}(\mathrm{mm})+4.241 \mathrm{~mm}(r=0.076, P=0.004)$. In normal eyes, the equation resulting from the linear regression analysis (orange line) was: $\mathrm{LT}(\mathrm{mm})=-0.117 \mathrm{AL}(\mathrm{mm})+7.281 \mathrm{~mm}(r=-0.166, P<0.001)$. In moderate myopic eyes, no significant correlation was found between LT and AL (green dotted line; $r=-0.006, P=0.760$ ). In highly myopic eyes, the equation resulting from the linear regression analysis (blue line) was: $\mathrm{LT}(\mathrm{mm})=0.040 \mathrm{AL}(\mathrm{mm})+3.235 \mathrm{~mm}(r=0.207, P<0.001)$. b Histogram showing the comparisons of $L T$ in different AL groups after adjusting for age and gender. AL, axial length; $L T$, lens thickness

Table 4 Associations between lens thickness and other ocular biometric factors in eyes with different axial lengths

\begin{tabular}{lll}
\hline & $\boldsymbol{\beta}$ & $\boldsymbol{P}$ value \\
\hline Short eyes & & \\
CCT (mm) & 0.078 & $<0.001$ \\
ACD (mm) & -0.680 & $<0.001$ \\
WTW (mm) & 0.192 & $<0.001$ \\
Anterior corneal curvature (mm) & -0.067 & 0.001 \\
Normal eyes & & \\
CCT (mm) & 0.051 & $<0.001$ \\
ACD (mm) & -0.690 & $<0.001$ \\
WTW (mm) & 0.204 & $<0.001$ \\
Anterior corneal curvature $(\mathrm{mm})$ & -0.079 & $<0.001$ \\
Moderate myopic eyes & & \\
CCT (mm) & 0.059 & $<0.001$ \\
ACD (mm) & -0.601 & $<0.001$ \\
WTW (mm) & 0.190 & $<0.001$ \\
Anterior corneal curvature (mm) & -0.146 & $<0.001$ \\
Highly myopic eyes & & $<0.001$ \\
CCT (mm) & 0.045 & $<0.001$ \\
ACD (mm) & -0.579 & $<0.001$ \\
WTW (mm) & 0.193 & $<0.112$ \\
Anterior corneal curvature (mm) & -001
\end{tabular}

CCT central corneal thickness; $A C D$ anterior chamber depth; WTW white-towhite. $\beta$ regression coefficient

* Multivariate analysis after adjusting for age, gender, and eye laterality (right/left) information for capsular bag sizes since it is difficult to directly measure capsular bag sizes due to the lack of convenient measurement devices. Large WTW may be associated with the development of larger anterior segments, which also indicates the incompatibility between fixed-size IOLs and large capsular bags, which may further affect IOL stability [39]. Thus, in cataract patients with a thicker lens, the IOL should be also chosen with caution. In addition, we also report the association between LT and cornea curvature, which may provide a clue to the role of LT in the anterior segment anatomy.

More importantly, our study revealed that the distribution of LT in dependence of AL was not simply linear. This trend can only be clearly revealed with such a large sample. Previously, some studies found greater LT was associated with shorter AL, but only with a narrow range of AL [27]. However, in our study, we found that with the elongation of AL, the LT firstly slightly increased to a maximum of $4.75 \pm 0.45 \mathrm{~mm}$ in the $20.01-22 \mathrm{~mm} \mathrm{AL}$ group, then gradually decreased to a minimum of $4.33 \pm$ $0.45 \mathrm{~mm}$ in the $26.01-28 \mathrm{~mm}$ AL group, and finally increased again and reached a peak when AL was greater than $35 \mathrm{~mm}$. As for short eyes, the correlation between LT and AL was positive but weak, possibly because the lens development could either be normal or abnormal in the early stages of these eyes [40]. Moreover, it seems that moderate myopic eyes tend to have thinner lenses than emmetropic eyes. The thinning of the lens in myopic eyes may be an indication of the lens trying to control overall refractive status towards emmetropia or achieve a clear image on the retina [41]. However, unlike the myopic eyes with $\mathrm{AL} \leq 26 \mathrm{~mm}$, the LT of highly myopic eyes increases with AL again, though future studies are needed to identify whether the increase of LT is 
related with the global expansion of highly myopic eyes or resulted from metabolic changes in the lens [42].

Furthermore, the nonlinear change of LT with $\mathrm{AL}$ may, to some extent, contribute to the prediction errors of the previous formulas that did not include LT [43]. The impact of LT on IOL calculation has been confirmed in recent studies. Hyperopic shift is associated with a thicker lens, while a myopic shift is associated with a thin lens, especially for the Haigis formula which did not include LT $[19,25,44]$. Even for formulas that included LT, the effect of LT on refractive error is varied with different ALs, with the greatest effect seen in eyes with AL less than $22 \mathrm{~mm}$ [18]. Besides, there is a positive correlation between LT and postoperative IOL position as demonstrated in previous studies [3, 26]. Thus, the nonlinear change of LT with AL may account for some bias in IOL power calculation for short or long eyes, and the regression models for predicting IOL position in normal eyes may not fit in these eyes with extreme ALs. Although the choice of IOL power formulas in short or long eyes has been given much attention, the contribution of LT to the bias of IOL power calculation is unrecognized. Therefore, our study suggests that LT may be a vital variable to be considered during IOL calculation in short or long eyes. Moreover, the individualized selection of IOL formulas and optimization of the formula coefficient or constant may be needed to reduce prediction bias.

\section{Conclusions}

In conclusion, based on a large sample of Chinese cataractous population, a thicker lens was found to be associated with older age, the male gender, thicker central cornea, shallower ACD, larger WTW, and flatter anterior corneal curvature. In addition, the distribution of LT against AL is not simply linear, with the thickest lens seen in eyes with AL ranging $20.01-22 \mathrm{~mm}$ and thinnest lens in eyes with AL ranging 26.01-28 mm. Future study is needed to analyze the refractive prediction error of different IOL formulas using preoperative LT in eyes with very thick or thin lenses and short or long AL. The correlation of the predicted IOL position using age, AL, $\mathrm{ACD}$, cornea curvature, and LT with postoperative lens position may also be needed.

\section{Acknowledgments}

Not applicable.

\section{Authors' contributions}

JM: Conduct of the research, data acquisition, interpretation, manuscript drafting, critical revision, and statistical analysis. LW: Conduct of the research, data acquisition, interpretation, manuscript drafting, and critical revision. $\mathrm{WH}$ : Data acquisition, interpretation and manuscript drafting. JQ: Data acquisition and manuscript drafting. YL: Concept, management, technical support, funding and supervision. XZ: Concept, design, critical revision of manuscript, funding, management, and supervision. JM and LW contributed equally to this work. All authors read and approved the final submission of this manuscript.

\section{Funding}

The Chinese National Natural Science Foundation (grant nos. 81970780 81870642, 81670835, Beijing, China), the Shanghai Talent Development Fund (grant no. 201604, Shanghai, China), the Outstanding Youth Medical Talents Program of Shanghai Health and Family Planning Commission (grant no. 2017YQ011, Shanghai, China). The sponsor or funding organization had no role in the design or conduct of this research.

\section{Availability of data and materials}

Available from the corresponding author on reasonable request.

\section{Declarations}

Ethics approval and consent to participate

The study was approved by the institutional review board of the Eye and Ear, Nose, and Throat (EENT) Hospital of Fudan University, Shanghai, China (ID: 2014055). Written informed consent was obtained from each patient.

\section{Consent for publication}

Not applicable.

\section{Competing interests}

All the authors declare that they have no competing interests.

\section{Author details}

'Eye Institute and Department of Ophthalmology, Eye \& ENT Hospital, Fudan University, 83 Fenyang Road, Xuhui District, Shanghai 200031, China. ${ }^{2}$ Key Laboratory of Myopia, Ministry of Health, Shanghai, China. ${ }^{3}$ Key Laboratory of Visual Impairment and Restoration, Shanghai, China. ${ }^{4}$ Key NHC key Laboratory of Myopia (Fudan University), Shanghai, China. ${ }^{5}$ Laboratory of Myopia, Chinese Academy of Medical Sciences, Shanghai, China.

Received: 26 December 2020 Accepted: 16 May 2021

Published online: 31 May 2021

\section{References}

1. Foreman J, Keel S, van Wijngaarden P, Bourne RA, Wormald R, Crowston J, et al. Prevalence and causes of visual loss among the indigenous peoples of the world: a systematic review. JAMA Ophthalmol. 2018;136(5):567-80.

2. Reitblat O, Assia El, Kleinmann G, Levy A, Barrett GD, Abulafia A. Accuracy of predicted refraction with multifocal intraocular lenses using two biometry measurement devices and multiple intraocular lens power calculation formulas. Clin Exp Ophthalmol. 2015:43(4):328-34.

3. Olsen T, Hoffmann P. C constant: new concept for ray tracing-assisted intraocular lens power calculation. J Cataract Refract Surg. 2014:40(5):76473.

4. Hoffer KJ. Clinical results using the Holladay 2 intraocular lens power formula. J Cataract Refract Surg. 2000;26(8):1233-7.

5. Barrett GD. An improved universal theoretical formula for intraocular lens power prediction. J Cataract Refract Surg. 1993;19(6):713-20.

6. Plat J, Hoa D, Mura F, Busetto T, Schneider C, Payerols A, et al. Clinical and biometric determinants of actual lens position after cataract surgery. $J$ Cataract Refract Surg. 2017;43(2):195-200.

7. Tripathi RC, Tripathi BJ. Lens morphology, aging, and cataract. J Gerontol. 1983;38(3):258-70

8. Klein BE, Klein R, Moss SE. Lens thickness and five-year cumulative incidence of cataracts: the Beaver Dam Eye Study. Ophthalmic Epidemiol. 2000;7(4): 243-8.

9. Shammas HJ, Shammas MC. Measuring the cataractous lens. J Cataract Refract Surg. 2015:41(9):1875-9.

10. Henriquez MA, Mejías JA, Rincon M, Izquierdo L Jr, Binder PS, et al. Correlation between lens thickness and lens density in patients with mild to moderate cataracts. Br J Ophthalmol. 2020:104(10):1350-7.

11. Lam S. Comparison of age-derived lens thickness to optically measured lens thickness in IOL power calculation: a clinical study. J Refract Surg. 2012;28(2): 154-5.

12. Ohno-Matsui K, Lai TY, Lai CC, Cheung CM. Updates of pathologic myopia. Prog Retin Eye Res. 2016;52:156-87. 
13. Ferreira TB, Hoffer KJ, Ribeiro F, Ribeiro P, O'Neill JG. Ocular biometric measurements in cataract surgery candidates in Portugal. PLoS One. 2017; 12(10):e0184837

14. Yin $G$, Wang $Y X$, Zheng $Z Y$, Yang $H$, Xu L, Jonas JB, et al. Ocular axial length and its associations in Chinese: the Beijing Eye Study. PLoS One. 2012;7(8): e43172.

15. Su DH, Wong TY, Foster PJ, Tay WT, Saw SM, Aung T. Central corneal thickness and its associations with ocular and systemic factors: the Singapore Malay Eye Study. Am J Ophthalmol. 2009;147(4):709-16.e1.

16. Hoffmann PC, Hütz WW. Analysis of biometry and prevalence data for corneal astigmatism in 23,239 eyes. J Cataract Refract Surg. 2010;36(9): 1479-85.

17. Touzeau O, Allouch C, Borderie V, Kopito R, Laroche L. Correlation between refraction and ocular biometry. J Fr Ophtalmol. 2003;26(4):355-63.

18. Vega $Y$, Gershoni A, Achiron A, Tuuminen R, Weinberger $Y$, Livny E, et al. High agreement between Barrett Universal II calculations with and without utilization of optional biometry parameters. J Clin Med. 2021;10(3):542.

19. Hipólito-Fernandes D, Luís ME, Serras-Pereira R, Gil P, Maduro V, Feijão J, et al. Anterior chamber depth, lens thickness and intraocular lens calculation formula accuracy: nine formulas comparison. Br J Ophthalmol. 2020 Nov 23:bjophthalmol-2020-317822. https://doi.org/10.1136/bjophtha Imol-2020-317822

20. Klein BE, Klein R, Moss SE. Correlates of lens thickness: the Beaver Dam Eye study. Invest Ophthalmol Vis Sci. 1998;39(8):1507-10.

21. Hashemi H, Khabazkhoob M, Miraftab M, Emamian MH, Shariati M, Abdolahinia T, et al. The distribution of axial length, anterior chamber depth, lens thickness, and vitreous chamber depth in an adult population of Shahroud, Iran. BMC Ophthalmol. 2012;12:50.

22. Akman A, Asena L, Güngör SG. Evaluation and comparison of the new swept source OCT-based IOLMaster 700 with the IOLMaster 500. Br J Ophthalmol. 2016;100(9):1201-5.

23. Ortiz A, Galvis V, Tello A, Viaña V, Corrales Ml, Ochoa M, et al. Comparison of three optical biometers: IOLMaster 500, Lenstar LS 900 and Aladdin. Int Ophthalmol. 2019;39(8):1809-18.

24. Cho YJ, Lim TH, Choi KY, Cho BJ. Comparison of ocular biometry using new swept-source optical coherence tomography-based optical biometer with other devices. Korean J Ophthalmol. 2018;32(4):257-64.

25. Kim SY, Lee SH, Kim NR, Chin HS, Jung JW. Accuracy of intraocular lens power calculation formulas using a swept-source optical biometer. PLoS One. 2020;15(1):e0227638.

26. Olsen T. Prediction of the effective postoperative (intraocular lens) anterior chamber depth. J Cataract Refract Surg. 2006;32(3):419-24.

27. Jonas JB, Nangia V, Gupta R, Sinha A, Bhate K. Lens thickness and associated factors. Clin Exp Ophthalmol. 2012;40(6):583-90.

28. Savini G, Hoffer KJ, Schiano-Lomoriello D. Agreement between lens thickness measurements by ultrasound immersion biometry and optical biometry. J Cataract Refract Surg. 2018;44(12):1463-8.

29. Shufelt C, Fraser-Bell S, Ying-Lai M, Torres M, Varma R; Los Angeles Latino Eye Study Group. Refractive error, ocular biometry, and lens opalescence in an adult population: the Los Angeles Latino Eye Study. Invest Ophthalmol Vis Sci. 2005;46(12):4450-60.

30. Warrier S, Wu HM, Newland HS, Muecke J, Selva D, Aung T, et al. Ocular biometry and determinants of refractive error in rural Myanmar: the Meiktila Eye Study. Br J Ophthalmol. 2008;92(12):1591-4.

31. Wong TY, Foster PJ, Johnson GJ, Seah SK. Refractive errors, axial ocular dimensions, and age-related cataracts: the Tanjong Pagar Survey. Invest Ophthalmol Vis Sci. 2003:44(4):1479-85.

32. Koretz JF, Neider MW, Kaufman PL, Bertasso AM, DeRousseau CJ, Bito LZ. Slit-lamp studies of the rhesus monkey eye. I. Survey of the anterior segment. Exp Eye Res. 1987;44(2):307-18.

33. Wong TY, Foster PJ, Johnson GJ, Klein BE, Seah SK. The relationship between ocular dimensions and refraction with adult stature: the Tanjong Pagar Survey. Invest Ophthalmol Vis Sci. 2001;42(6):1237-42.

34. Satou T, Shimizu K, Tsunehiro S, Igarashi A, Kato S, Koshimizu M, et al. Relationship between crystalline lens thickness and shape and the identification of anterior ocular segment parameters for predicting the intraocular lens position after cataract surgery. Biomed Res Int. 2019;2019: 3458548.

35. Retzlaff JA, Sanders DR, Kraff MC. Development of the SRKJT intraocular lens implant power calculation formula. J Cataract Refract Surg. 1990; 16(3):333-40.
36. Hoffer KJ. The Hoffer Q formula: a comparison of theoretic and regression formulas. J Cataract Refract Surg. 1993;19(6):700-12.

37. Nangia V, Jonas JB, Sinha A, Matin A, Kulkarni M. Central corneal thickness and its association with ocular and general parameters in Indians: the Central India Eye and Medical Study. Ophthalmology. 2010;117(4):705-10.

38. Jonas JB, Nangia V, Gupta R, Khare A, Sinha A, Agarwal S, et al. Anterior chamber depth and its associations with ocular and general parameters in adults. Clin Exp Ophthalmol. 2012;40(6):550-6.

39. Zhu X, He W, Zhang Y, Chen M, Du Y, Lu Y. Inferior decentration of multifocal intraocular lenses in myopic eyes. Am J Ophthalmol. 2018; 188:1-8.

40. Singh OS, Simmons RJ, Brockhurst RJ, Trempe CL. Nanophthalmos: a perspective on identification and therapy. Ophthalmology. 1982;89(9): 1006-12.

41. Muralidharan G, Martínez-Enríquez E, Birkenfeld J, Velasco-Ocana M, PérezMerino P, Marcos S. Morphological changes of human crystalline lens in myopia. Biomed Opt Express. 2019;10(12):6084-95.

42. Zhu X, Li D, Du Y, He W, Lu Y. DNA hypermethylation-mediated downregulation of antioxidant genes contributes to the early onset of cataracts in highly myopic eyes. Redox Biol. 2018;19:179-89.

43. Gökce SE, Zeiter JH, Weikert MP, Koch DD, Hill W, Wang L. Intraocular lens power calculations in short eyes using 7 formulas. J Cataract Refract Surg. 2017;43(7):892-7.

44. Melles RB, Holladay JT, Chang WJ. Accuracy of intraocular lens calculation formulas. Ophthalmology. 2018;125(2):169-78.
Ready to submit your research? Choose BMC and benefit from:

- fast, convenient online submission

- thorough peer review by experienced researchers in your field

- rapid publication on acceptance

- support for research data, including large and complex data types

- gold Open Access which fosters wider collaboration and increased citations

- maximum visibility for your research: over $100 \mathrm{M}$ website views per year

At BMC, research is always in progress.

Learn more biomedcentral.com/submissions 